\title{
Mating and Pseudothecial Development in Mycosphaerella citri, the Cause of Citrus Greasy Spot
}

\author{
S. N. Mondal, D. S. Howd, R. H. Brlansky, and L. W. Timmer
}

First and second authors: Senior Biological Scientists, and third and fourth authors: Professors, University of Florida, Citrus Research and Education Center and Department of Plant Pathology, Lake Alfred 33850. Accepted for publication 11 May 2004.

\section{ABSTRACT}

Mondal, S. N., Howd, D. S., Brlansky, R. H., and Timmer, L. W. 2004. Mating and pseudothecial development in Mycosphaerella citri, the cause of citrus greasy spot. Phytopathology 94:978-982.

Greasy spot, caused by Mycosphaerella citri, is a serious disease of citrus in the Caribbean basin. $M$. citri is a loculoascomycete and produces pseudothecia in decomposing leaves after intermittent wetting and drying. A new in vitro mating technique was developed for production of pseudothecia on sterilized leaf disks in petri dishes. Of the single-ascospore cultures that were recovered from individual asci, four were one mating type and four were a second mating type (tentatively designated mat+ and mat-), indicating that $M$. citri probably is heterothallic and bipolar like most other loculoascomycetes. Most populations of ascospores recovered from individual leaves or from leaves from groves of different citrus species and various locations had a 1:1 ratio of mating types consistent with random mating. Cytological studies demonstrated that the ontogeny of pseudothecial development was similar to other loculoascomycetes. The formation of mature pseudothecia required 30 to 45 cycles of wetting and drying of infected, dead leaves which required $\approx 60$ to 90 days. The in vitro system for pseudothecial production and the knowledge of the mating system in $M$. citri will facilitate genetic studies of this important pathogen.
Greasy spot, caused by Mycosphaerella citri Whiteside, produces oily lesions on the underside of citrus leaves that result in premature defoliation (16). Leaf loss eventually reduces tree vigor, yield, and fruit size. $M$. citri also infects fruit, causing greasy spot rind blotch, which reduces the acceptability of fruit for the fresh market. The disease affects all citrus, but is most severe on grapefruit and its hybrids. Greasy spot is economically important on all of the 320,000 ha of citrus in Florida as well as in eastern Mexico, Central America, and the Caribbean islands. Similar diseases occur in Argentina, Australia, and Japan (16).

M. citri, a loculoascomycete, produces ascospores in leaf litter on the grove floor $(10,11,17)$. In Florida, most of the leaf drop occurs in January to February and peak ascospore release occurs in April to May $(10,17)$. Whiteside (22) demonstrated that alternate wetting and drying was needed for pseudothecial development in dead, infected leaves. Mondal and Timmer (11) found that wetting of diseased leaves three times per week for 30 to 60 min maximized pseudothecial production. Most ascospores are released in a few hours after leaves are wetted once the pseudothecia are mature (10).

The mating systems and pseudothecial development of several loculoascomycete plant pathogens have been investigated. Venturia inaequalis was found to be heterothallic with a bipolar mating system many years ago (6) and a technique was developed later to produce pseudothecia under artificial conditions (14). The cytology of pseudothecial development and the conditions under which pseudothecia develop have been extensively studied $(5,8$, 18,25). Didymella rabiei, the cause of Ascochyta blight of chickpea, was found to be heterothallic and bipolar, and an in vitro system has been developed to produce pseudothecia (18). M. graminicola was found to be heterothallic and bipolar, but pseudothecia cannot be produced in vitro, complicating genetic studies (7). The

Corresponding author: L. W. Timmer; E-mail address: 1wt@crec.ifas.ufl.edu

Publication no. P-2004-0707-01R

(c) 2004 The American Phytopathological Society causal agents of black leaf streak and Sigatoka disease of banana, M. fijiensis and M. musicola, respectively, have been well studied (9), and an in vitro system for production of pseudothecia has been developed for $M$. fijiensis (3). This species also was found to be heterothallic and bipolar $(3,12)$.

The conditions required for pseudothecial development and ascospore release of $M$. citri have been elucidated in recent studies $(10,11,22)$. However, no technique for the in vitro production of pseudothecia has been developed and the mating system has never been investigated. Previous histological studies have been conducted on the infection process and on pseudothecial structure (23), but detailed studies of the ontogeny of pseudothecial development are lacking.

The purpose of this study was to develop a technique for pseudothecial production in vitro and determine whether $M$. citri was homothallic or heterothallic. The distribution of mating types within asci, within individual leaves, and among groves was investigated to ascertain the segregation and distribution of mating types. Cytological studies were conducted to follow the development of ascocarps in relation to wetting and drying cycles.

\section{MATERIALS AND METHODS}

Isolation and maintenance of single-ascospore cultures. Cultures from single ascospores were obtained by collecting leaves with mature pseudothecia, soaking them in water for 10 to 15 min, blotting them dry, and affixing them to the lid of a petri dish using petroleum jelly. Ascospores were ejected onto 5\% water agar when leaves were incubated overnight at room temperature $\left(23\right.$ to $\left.25^{\circ} \mathrm{C}\right)$. Individual germinated ascospores were transferred with the aid of a stereo microscope to dishes of potato dextrose agar (PDA) containing $0.1 \%$ tartaric acid. After the colonies had grown out, each isolate was transferred to a dish of PDA. A sterile 3-by-3-cm piece of filter paper was placed on the surface of the agar and pieces of mycelium were deposited at the edge of a filter paper (13). The dishes were incubated at $27^{\circ} \mathrm{C}$ until the culture had colonized the filter paper. Then the filters 
were lifted from the agar surface with a sterile forceps, placed in a sterile coin envelope, and dried overnight in a laminar flow hood. Envelopes were placed in a closed plastic container with $\mathrm{CaSO}_{4}$ as a drying agent (Hammond Drierite, Xenia, OH) and stored at $-20^{\circ} \mathrm{C}$ until needed.

In vitro mating technique. A method was developed to produce pseudothecia in vitro to determine the mating behavior and the mating type for individual isolates. Healthy, mature grapefruit leaves were collected and leaf disks, $1 \mathrm{~cm}$ in diameter, were cut using a cork borer and autoclaved for $15 \mathrm{~min}$. Two sterile filter papers were placed in a petri dish and moistened with sterile water. Five autoclaved leaf disks were placed in each petri dish. Plugs ( $2 \mathrm{~mm}$ in diameter) were cut from PDA cultures of single-ascospore isolates of $M$. citri. The plug from one singleascospore culture was placed $5 \mathrm{~mm}$ distant from the other on the upper surface of the leaf disk. These mating cultures were incubated at 23 to $25^{\circ} \mathrm{C}$ in the laboratory for 7 to 10 days, after which time the lids were removed and the leaf disks were allowed to dry. Subsequently, the cultures were moistened with 2 to $3 \mathrm{ml}$ of sterile water every other day and allowed to dry each time at 23 to $25^{\circ} \mathrm{C}$ on the laboratory bench. Pseudothecial development typically was observed in compatible matings after 30 to 40 days.

Mating type distribution. The mating type of field-collected isolates was determined using the in vitro system and by pairing single-ascospore isolates with standard testers. Single-ascospore isolates GFO2 and GFO26, which produced abundant mature pseudothecia when mated using the in vitro system, were tentatively designated as mat+ and mat-, respectively. All matings were performed twice to confirm the mating type of the culture.

To determine if mating type segregated within asci, ascospores were ejected onto water agar as indicated above. Clusters of eight ascospores were located on the water agar and presumed to have arisen from a single ascus. Single ascospores were separated with a fine needle, transferred to individual PDA dishes, and grown into colonies. In three cases, cultures were obtained from all eight ascospores, and these cultures were mated with the standard isolates in the in vitro system to determine mating type.

To determine the mating type distribution within individual leaves, three symptomatic leaves of grapefruit trees in Lake Alfred, FL were subjected to alternate wetting and drying to produce mature pseudothecia (11). Single-ascospore isolates were obtained from these leaves as described above. A total of 230, 315 , and 49 isolates were obtained from leaves 1,2 , and 3 , respectively, and the mating type of each determined using the mating technique.

Single-ascospore isolates were collected from leaves of different citrus species and different citrus areas within the state. From 39 to 105 isolates were collected from each source and all were tested for mating type using the standard isolates in the in vitro system.

Pseudothecial development. Mature grapefruit leaves with severe greasy spot were collected and air dried at ambient temperature. Leaves were soaked for $2 \mathrm{~h}$ and then air dried at $28^{\circ} \mathrm{C}$ for 2 days (11). Wetting and drying cycles were continued for 90 days. Periodically throughout the 90 -day study, five- to sevenleaf disks, $3 \mathrm{~mm}$ in diameter, were cut from the leaves. This tissue was examined with a dissecting microscope and crushed, stained with cotton blue-lactophenol, and examined under a compound microscope at $\times 100$ to determine the stage of development of pseudothecia. As each stage was reached, the number of days and wetting-drying cycles for that stage was recorded. Not all pseudothecia were in the same stage of development at any given time. The experiment was repeated three times.

For photographic documentation of the developmental stages, leaf tissues were fixed in $3 \%$ glutaraldehyde in $0.066 \mathrm{M}$ potassium phosphate buffer, $\mathrm{pH} 7.2$, for 4 to $8 \mathrm{~h}$ at $26^{\circ} \mathrm{C}$. The samples then were washed in the same buffer and post fixed in $2 \% \mathrm{OsO}_{4}$ in the same buffer for $4 \mathrm{~h}$ at $26^{\circ} \mathrm{C}$ or overnight at $4^{\circ} \mathrm{C}$ (1). The samples were dehydrated in an acetone series and embedded in
Spurr's resin. Sections $(0.75 \mu \mathrm{m}$ thick $)$ were cut from samples representing each time period on an ultramicrotome (Reichert Optische Werke AG, Vienna, Austria) with glass knives and stained with methylene blue-azure A and basic fuchsin (15). Sections were observed using an Olympus AH-2 Vanox microscope and photographed using a Nikon Coolpix 995 digital camera.

\section{RESULTS}

In vitro mating technique. Mature fertile pseudothecia were produced on autoclaved leaf disks when some single-ascospore cultures were mated (Fig. 1A). The size and shape of the pseudothecia, asci, and ascospores corresponded well with the original description of $M$. citri (23). Incompatible crosses produced barren pseudothecia that contained no asci or ascospores (Fig. 1B). Ascospores were ejected from mature pseudothecia produced by this system as readily as from naturally infected material.

Distribution of mating types. Ascospores from three asci were successfully separated and grown. When mated in the in vitro system, all three had a ratio of 4:4 mat+:mat-, indicating that mating type segregated within each ascus. Thus, M. citri apparently is heterothallic with a bipolar mating system.

When single ascospores were recovered from individual fieldcollected grapefruit leaves, the ratio was not significantly different from 1:1 at $P \leq 0.05$ in two of three leaves (Table 1). The ratio of mating types was significantly different from $1: 1$ in one leaf, but fewer ascospores were tested from that leaf. Matings produced mature pseudothecia with one tester or the other in 78 to $100 \%$ of the crosses made.
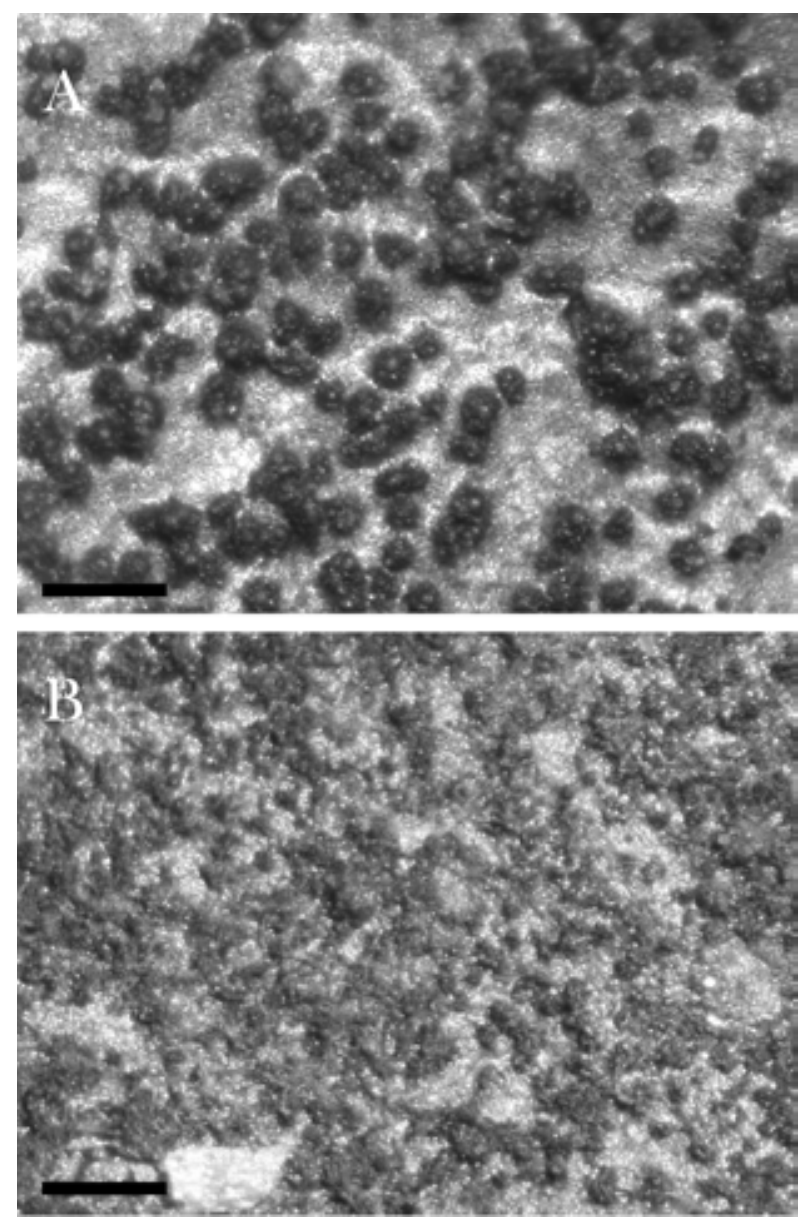

Fig. 1. Pseudothecia of Mycosphaerella citri produced using the in vitro mating technique. A, Mature pseudothecia produced by mating of compatible types. B, Barren pseudothecia produced following pairings of incompatible types. Bar equals $200 \mu \mathrm{m}$ in $\mathbf{A}$ and $\mathbf{B}$. 
The ratio of mating types of single-ascospore isolates collected from different citrus species in various areas of Florida did not differ significantly from $1: 1$ at $P \leq 0.05$ in eight of the nine locations (Table 2). The percentage of the isolates that mated successfully with one of the two testers ranged from 71 to $98 \%$.

Development of pseudothecia. After the dried symptomatic leaves were exposed to the wetting-drying cycles, stromatic initials (Fig. 2A) were formed quickly after 1 to 2 wet-dry cycles ( 2 to 4 days) (Fig. 3). Ascogonium formation and lumen initials (Fig. 2B and C) followed relatively quickly after 9 to 12 wet-dry cycles (18 to 24 days) (Fig. 3). The formation of pseudoparaphyses and asci (Fig. 2D) required more time and there was greater variability among pseudothecia in reaching this stage. A total of 17 to 24 wet-dry cycles ( 34 to 48 days) were required to form asci (Fig. 3). From 10 to 15 additional cycles (54 to 78 days total) were required for differentiation, development, and maturation of asci (Fig. $2 \mathrm{E}$ to $\mathrm{G}$ ). After $\approx 30$ to 45 wet-dry cycles ( 60 to 90 days), pseudothecia had ejected their ascospores and were empty (Fig. 2H).

\section{DISCUSSION}

A new technique was developed that permitted production of pseudothecia and ascospores in vitro as has been done with $V$. inaequalis $(6,14)$, D. rabiei $(18)$, and $M$. fijiensis $(3,12)$. We believe that alternate wetting and drying was a key factor in the success of the technique. In nature, it is important because fallen leaves that remain wet continuously are colonized by other fungi and decay before they produce pseudothecia (11). The other systems developed $(3,7,12,14,18)$ do not utilize this procedure but, in some cases $(7,18)$, inoculated plant tissues were placed under field conditions where they would be exposed to such conditions. We found that incompatible matings produced barren pseudothecia. Such structures have been reported with $V$. inaequalis (6) but are not mentioned in reports with other loculoascomycetes $(3,7,12,14,18)$.

The in vitro mating technique allowed us to investigate the mating system of $M$. citri as has been done with other loculoascomycetes $(3,7,12,18)$. All of our results are consistent with the hypothesis that $M$. citri is heterothallic and bipolar. We found two mating types that we have tentatively designated as mat+ and mat-. The mating type locus from $M$. citri has not been cloned and sequenced; therefore, we cannot identify which mating-type idiomorph is homologous to MAT-1 or MAT-2 in other asco- mycetes (20). Our preliminary attempts to amplify MAT genes from $M$. citri using primers designed from $M$. graminicola have been unsuccessful.

Our studies of ascospores from putatively single asci suggest that mating type segregates within a single ascus. Tetrad analysis will be needed to confirm these results. Only two mating types have been identified from the many matings that we have conducted with single-ascospore cultures from a wide geographical range in Florida. Reciprocal crosses among three single-ascospore cultures and numerous matings of arbitrarily selected cultures have not identified other mating types (unpublished data), suggesting that only two alleles occur at the MAT locus, as has been found in other heterothallic loculoascomycetes (24). Large numbers of reciprocal crosses with single-ascospore cultures are needed to confirm the absence of other mating types. Our findings are consistent with those of $V$. inaequalis $(6,14,24)$, D. rabiei (18), M. fijiensis $(3,12)$, and $M$. graminicola $(6,20)$, all of which are heterothallic and bipolar. In these species, one individual carries either the MAT-1 or MAT-2 idiomorph at the MAT locus, but never both (19). In contrast, homothallic Cochliobolus spp. carry both idiomorphs in the same nucleus, but the structural organization of the MAT locus is different. In Cochliobolus luttrelli and C. homomorphous, the idiomorphs are fused, in C. kusanoi they are tightly linked, and in C. cymbopogonis they are unlinked (18). In the one known homothallic species of Mycosphaerella, M. zeae-maydis, the idiomorphs are linked but separated by $\approx 1 \mathrm{~kb}$ of noncoding DNA (19). In our studies, not all of the matings were fertile with either tester and, occasionally, the mating type ratio did not fit a 1:1 distribution. Thus, there may be other genes in $M$. citri that affect fertility of the fungus, and random mating may not be occurring in all populations.

From our matings of single-ascospore cultures obtained from field samples, mating type ratios were consistent with random mating. However, $\chi^{2}$ tests of mating type ratios lack statistical power, and other approaches with additional unlinked molecular markers and large numbers of isolates from single populations will be required to rigorously test the random mating hypothesis in $M$. citri. Development of a $M A T$-specific polymerase chain reaction assay in $M$. citri would facilitate examination of larger numbers of isolates to determine whether mating is random, as has been done with $M$. graminicola (21). Characterization of the MAT locus also may be useful for phylogenetic studies of $M$. citri and other Mycosphaerella spp. affecting citrus (16), as has been done with other loculoascomycetes (2).

TABLE 1. Fertility and frequency of mating types among single-ascospore isolates of Mycosphaerella citri collected from individual grapefruit leaves

\begin{tabular}{|c|c|c|c|c|c|c|}
\hline \multirow[b]{2}{*}{ Leaf } & \multirow[b]{2}{*}{$n$} & \multirow[b]{2}{*}{ Successful mating (\%) } & \multicolumn{2}{|c|}{ Mating type $^{\mathrm{a}}$} & \multirow[b]{2}{*}{$\chi^{2}$} & \multirow[b]{2}{*}{$P$} \\
\hline & & & mat+ & mat- & & \\
\hline GF L-1 & 230 & 83 & 95 & 105 & 0.50 & 0.45 \\
\hline
\end{tabular}

a Determined with standard tester isolates GFO2 and GFO26 using the in vitro mating technique.

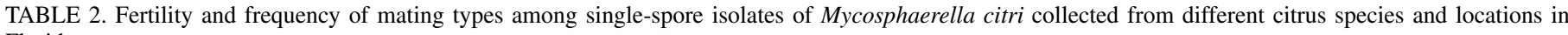
Florida

\begin{tabular}{|c|c|c|c|c|c|c|}
\hline Citrus species & Grove location & Total cross & Successful matings (\%) & Mating type $(\text { mat }+: m a t-)^{\mathrm{a}}$ & $\chi^{2}$ & $P$ \\
\hline Grapefruit 2B & Lake Alfred & 58 & 82 & $20: 28$ & 1.35 & 0.25 \\
\hline Grapefruit 19 & Lake Alfred & 39 & 77 & $17: 13$ & 0.56 & 0.45 \\
\hline Lime & Lake Alfred & 60 & 85 & $31: 20$ & 2.39 & 0.20 \\
\hline Lemon & Lake Alfred & 61 & 98 & $29: 31$ & 0.04 & 0.90 \\
\hline Sweet orange & Lake Alfred & 42 & 95 & $20: 20$ & 0.00 & 1.0 \\
\hline Sweet orange & Immokalee & 105 & 92 & $59: 38$ & 4.55 & 0.05 \\
\hline Murcott & Bereah & 42 & 73 & $19: 10$ & 2.74 & 0.10 \\
\hline Grapefruit & Fort Pierce & 83 & 85 & $35: 36$ & 0.01 & 0.90 \\
\hline Tangelo & Polk City & 79 & 71 & $33: 23$ & 1.61 & 0.25 \\
\hline
\end{tabular}

a Determined with standard isolates GF02 and GF026 in the in vitro mating system. 

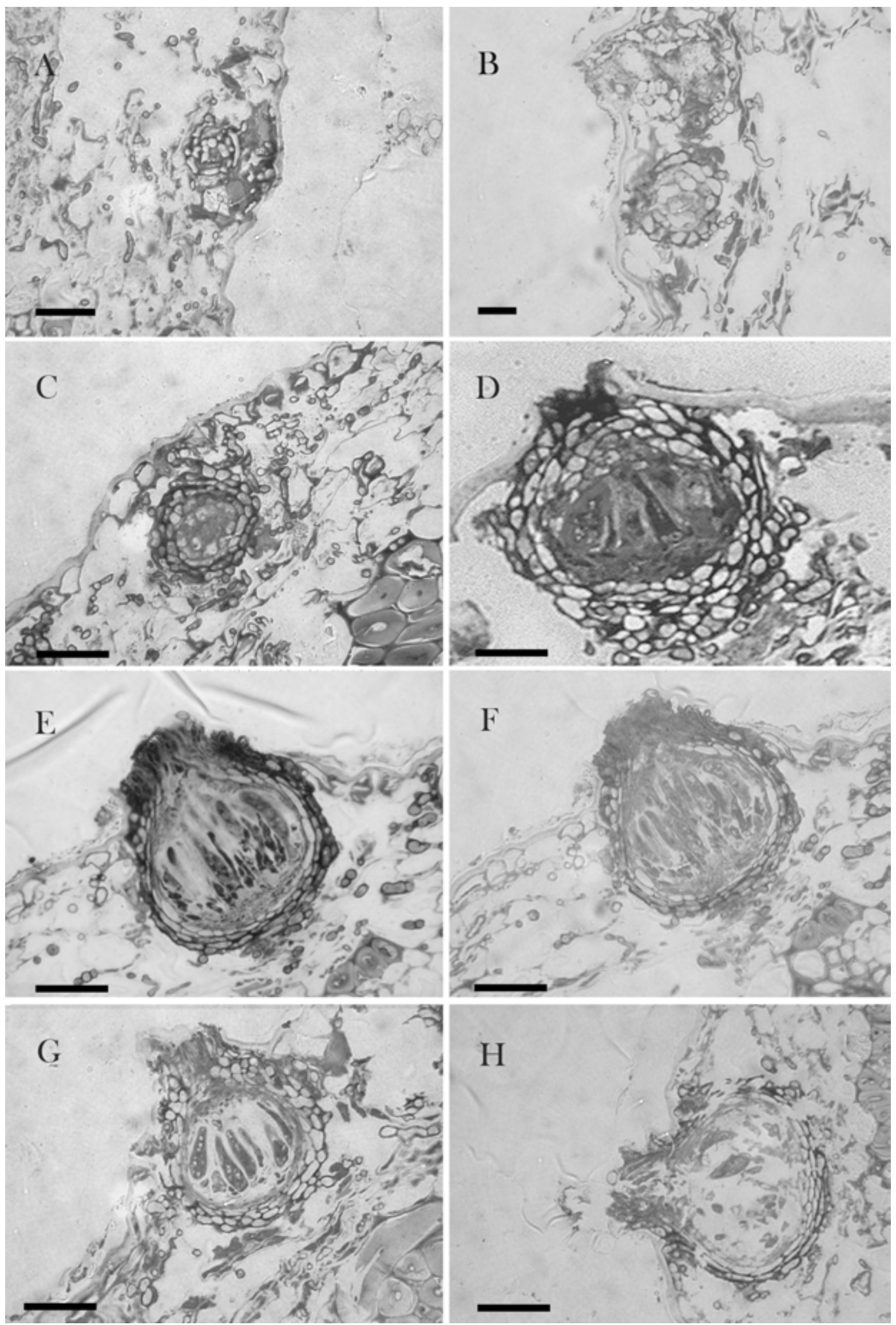

Fig. 2. Ontogeny of pseudothecial development of Mycosphaerella citri in decomposing grapefruit leaves. A, Stromatic initial, B, ascogonial initial, $\mathbf{C}$, lumen initial, D, formation of pseudoparaphyses and asci, $\mathbf{E}$ and $\mathbf{F}$, asci mature but not ready for release, $\mathbf{G}$, mature asci and ascospores, and $\mathbf{H}$, exhausted pseudothecium. All bars equal $25 \mu \mathrm{m}$. 


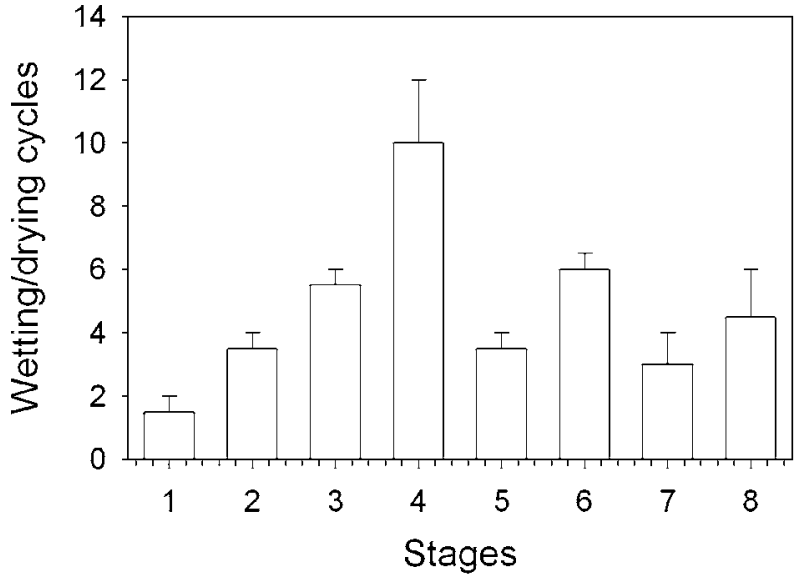

Fig. 3. Number and range of wet-dry cycles required for each stage of development of pseudothecia of Mycosphaerella citri; $1=$ stromatic initials, $2=$ ascogonium formation, $3=$ lumen initials, $4=$ formation of pseudoparaphyses and asci, $5=$ asci developed, contents not yet differentiated, $6=$ asci developed, but ascospores not ready to release, $7=$ mature asci, and $8=$ pseudothecia exhaustion.

The stages of development of pseudothecia of $M$. citri are similar to those in other loculoascomycetes $(5,18,24)$. Many of these fungi are pathogens of temperate crops; thus, pseudothecial development occurs at cold, winter temperatures. Ascospore release in those fungi is timed with the phenology of the host as temperatures rise in the spring. With $M$. citri, temperature affects the rate of pseudothecial development (11), but ascospore production is unrelated to the phenology of citrus, a subtropical evergreen. Even under optimal conditions of wetting-drying and temperature, a minimum of 60 days is required for ascospore maturity. Under natural conditions, development is much slower (9). The time required for pseudothecial development is similar to that of $V$. inaequalis $(4,8,25)$ and $D$. rabiei $(18)$, even though $M$. citri pseudothecia generally develop under warmer conditions. Pseudothecial maturation is not synchronous even under controlled conditions. This is consistent with our previous finding that, once the first ascospores in a leaf mature, ascospores continue to be released for three to four more cycles of wetting and drying (10).

\section{ACKNOWLEDGMENTS}

This research was supported by the Florida Agricultural Experiment Station and a grant from the Florida Citrus Production Advisory Council, Project 013-16P, and approved for publication as Journal Series R-10001. We thank T. L. Peever, Washington State University, and T. B. Sutton, North Carolina State University, for helpful discussions; and C. L. Geanangel and L. Zhang for technical assistance.

\section{LITERATURE CITED}

1. Achor, D. S., Browning, H., and Albrigo, L. G. 1997. Anatomical and histochemical effects of feeding by Citrus leaf miner larvae (Phyllocnistis citrella Stainton) in Citrus leaves. J. Am. Hortic. Soc. 122:829:836.

2. Barve, M. P., Arie, T., Salimath, S., Muehlbauer, F. J., and Peever, T. L. 2003. Cloning and characterization of the mating type (MAT) locus from Ascochyta rabiei (teleomorph: Didymella rabiei) and a MAT) phylogeny of legume-associated Ascochyta spp. Fungal Genet. Biol. 39:151-167.
3. Etebu, E., Pasberg-Gauhl, F., and Daniel-Kalio, L. A. 2003. Preliminary studies of in vitro stimulation of sexual mating among isolates of Mycosphaerella fijiensis, causal agent of Black Sigatoka Disease in bananas and plantains. Phytoparasitica 31:1-7.

4. Gadoury, D. M., and MacHardy, W. E. 1982. Preparation and interpretation of squash mounts of pseudothecia of Venturia inaequalis. Phytopathology 72:92-95.

5. James, J. R., and Sutton, T. B. 1982. Environmental factors influencing pseudothecial development and ascospore maturation of Venturia inaequalis. Phytopathology 72:1073-1080.

6. Keitt, G. W., and Palmiter, D. H. 1938. Heterothallism and variability in Venturia inaequalis. Am. J. Bot. 25:338-345.

7. Kema, G. H. J., Verstrappen, E. C. P., Todorova, M., and Waalwijk, C. 1996. Successful crosses and molecular tetrad and progeny analyses demonstrate heterothallism in Mycosphaerella graminicola. Curr. Genet. 30:251-258

8. MacHardy, W. E., Gadoury, D. M., and Gessler, C. 2001. Parasitic and biological fitness of Venturia inaequalis: Relationship to disease management strategies. Plant Dis. 85:1036-1051.

9. Marin, D. H., Romero, R. A., Guzmán, M., and Sutton, T. B. 2003. Black Sigatoka: An increasing threat to banana cultivation. Plant Dis. 87:208221.

10. Mondal, S. N., Gottwald, T. R., and Timmer, L. W. 2003. Environmental factors affecting the release and dispersal of ascospores of Mycosphaerella citri. Phytopathology 93:1031-1036.

11. Mondal, S. N., and Timmer, L. W. 2002. Environmental factors affecting pseudothecial development and ascospore production of Mycosphaerella citri, the cause of citrus greasy spot. Phytopathology 92:1267-1275.

12. Mourichon, X., and Zapater, M. F. 1990. Obtention in vitro du stade Mycosphaerella fijiensis, forme parfaite de Cercospora fijiensis. Fruits 45:553-557.

13. Peever, T. L., Canihos, Y., Olsen, L., Ibáñez, A., Liu, Y.-C., and Timmer, L. W. 1999. Population genetic structure and host specificity of Alternaria spp. causing brown spot of Minneola tangelo and rough lemon in Florida. Phytopathology 89:851-860.

14. Ross, R. G., and Hamlin, S. A. 1962. Production of perithecia of Venturia inaequalis (Cke) Wint. on sterile apple leaf discs. Can. J. Bot. 40:629635.

15. Schneider, H. 1981. Plant anatomy and general botany. Pages 315-373 in: Stain Procedures for Biological Stain Commission. 4th ed. G. Clark, ed. Williams and Wilkins, Baltimore.

16. Timmer, L. W., and Gottwald, T. R. 2000. Greasy spot and similar diseases. Pages 25-28 in: Compendium of Citrus Diseases. L. W. Timmer, S. M. Garnsey, and J. H. Graham, eds. The American Phytopathological Society, St. Paul, MN.

17. Timmer, L. W., Roberts, P. D., Darhower, H. M., Bushong, P. M., Stover, E. W., Peever, T. L., and Íbañez, A. M. 2000. Epidemiology and control of citrus greasy spot in different citrus-growing areas in Florida. Plant Dis. 84:1294-1298.

18. Trapero-Casas, A., and Kaiser, W. J. 1992. Development of Didymella rabiei, the teleomorph of Ascochyta rabiei on chickpea straw. Phytopathology 82:1261-1266.

19. Turgeon, B. G. 1998. Application of mating type gene technology to problems in fungal biology. Annu. Rev. Phytopathol. 36:115-137.

20. Turgeon, B. G., and Yoder, O. C. 2000. Proposed nomenclature for mating type genes of filamentous Ascomycetes. Fungal Genet. Biol. 31:1-5.

21. Waalwijk, C., Mendes, O., Verstrappen, E. C. P., de Waard, M. A., and Kema, G. H. J. 2002. Isolation and characterization of the mating-type idiomorphs from the wheat Septoria leaf blotch fungus Mycosphaerella graminicola. Fungal Genet. Biol. 35:277-286.

22. Whiteside, J. O. 1970. Etiology and epidemiology of citrus greasy spot. Phytopathology 60:1409-1414.

23. Whiteside, J. O. 1972. Histopathology of citrus greasy spot and identification of the causal fungus. Phytopathology 62:260-263.

24. Wilson, A. D., and Kaiser, W. J. 1995. Cytology and genetics of sexual compatibility in Didymella rabiei. Mycologia 87:795-804.

25. Wilson, E. E. 1928. Studies of the ascigerous stage of Venturia inaequalis (Cke.) Wint. in relation to certain factors in the environment. Phytopathology 18:375-417. 